\title{
(ब)]
}

\section{UTILIZAÇÃO DA ABORDAGEM DE PROCESSO DE DESENVOLVIMENTO DE PRODUTO (PDP) PARA A CRIAÇÃO DE UM PROTÓTIPO DE CARATER ERGONÔMICO INOVADOR}

\section{THE UTILIZATION OF PRODUCT DEVELOPMENT PROCESS APROACH (PDP) FOR CREATING AN INNOVATIVE ERGONOMIC PROTOTYPE}

\author{
SILVA, Pedro Henrique (1); \\ PAIVA, Lucas Pimenta Silva (2); \\ CRUZ, Rodrigo Lopes Oliveira da (3); \\ EVANGELISTA, Wemerton Luis (4) \\ (1) IFMG - Bambuí, Graduando em Engenharia de Produção \\ e-mail:pedrohenriquegol@hotmail.com \\ (2) IFMG - Bambuí, Graduando em Engenharia de Produção \\ e-mail:lucas.paiva.aguanil@gmail.com \\ (3) IFMG - Bambuí, Graduando em Engenharia de Produção \\ e-mail:rodrigolopes.cruz@gmail.com \\ (4) IFMG - Bambuí, Doutor em Engenharia (Ergonomia) \\ e-mail:wemerton.evangelista@ifmg.edu.br
}

\begin{abstract}
RESUMO
A aplicação dos conceitos da ergonomia dentro do ambiente empresarial possuiu inúmeros benefícios, pois visa a adaptação do ambiente de trabalho e a estruturação correta de equipamentos e demais produtos ao funcionário, tornando-o mais produtivo e motivado para a execução das tarefas propostas e reduzindo os riscos de acidentes de trabalho. Nesse contexto, o presente artigo tem como objetivo o desenvolvimento de um protótipo, o qual auxilia no levantamento e transporte manual de cargas, possibilitando ao seu usuário uma otimização da "pega" para tais atividades. 0 protótipo consiste em um pegador a vácuo capaz de levantar pesos de até $20 \mathrm{Kg}$.
\end{abstract}

Palavras chave: Ergonomia, Otimização, Levantamento de carga.

\section{ABSTRACT}

The ergonomics has several benefits when applied into the business environment, reducing the occurence of work related accidents by adapting the working environment and providing well adapted 


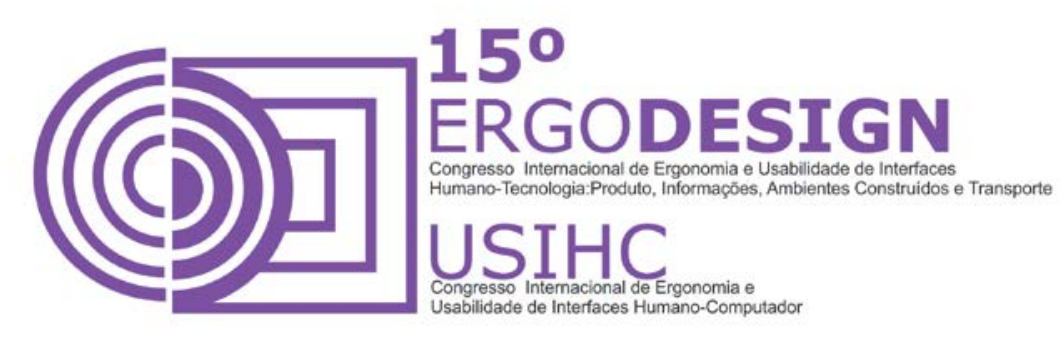

tools and equipments to the employees, becoming well motivated and productive while performing given tasks. In this context, the main goal of this article is the development of a prototype that will assist the user to manually lift and transport cargos, allowing him the optmization of the "grip" for such activities. The prototype consists in a vaccum holder capable of lifting loads up to $20 \mathrm{Kg}$.

Key words: Ergonomics, Optimization, Cargo lifting.

\section{INTRODUÇÃO}

A Associação Brasileira de Ergonomia (ABERGO, 2000) define a ergonomia como uma disciplina científica que relaciona as interações dos seres humanos com outros elementos ou sistemas, e à aplicação de teorias, princípios e técnicas, com o propósito de otimizar o bem-estar humano e a produtividade do sistema. Portando, pode-se concluir que a ergonomia se trata de uma ciência que estuda meios de adaptar o trabalho ao homem, garantindo sua saúde e segurança.

Desde o início do século XXI, o desenvolvimento de projetos de produto tem em seu âmbito, a procura de desenvolver produtos que proporcionem maior eficiência, qualidade $\mathrm{e}$ segurança para o usuário, uma vez que os mercados apresentam-se cada vez mais competitivos, as exigências normativas tornam-se cada vez mais rigorosas, e as inovações tecnológicas são cada vez mais, frequentes e levados ao consumidor. Segundo lida (2005) a qualidade ergonômica do produto garante a boa interação do produto com o usuário, eliminando ou diminuindo a carga física que o mesmo sofre ao realizar uma atividade ou exercício.

A Organização Internacional do Trabalho (OIT) determina que os acidentes gerados pela manipulação de cargas, está entre $20 \%$ a $25 \%$ de todos os acidentes de trabalho. Estudos notórios já foram realizados a fim de determinar as melhores condições de trabalho. Como, por exemplo, o método desenvolvido pelo Instituto Nacional para Segurança e Saúde Ocupacional (NIOSH). Este método consiste em uma equação que determina qual é o limite de peso recomendado para o levantamento de cargas. A equação conta com algumas variáveis. Entretanto, para a realização do trabalho será levado em conta apenas uma variável da equação, o fator "pega". Esse fator determina a facilidade com que o trabalhador tem para agarrar e levantar o objeto, sendo que quanto maior o fator, maior será a facilidade de mobilização do mesmo.

Sendo assim, o trabalho teve como principal objetivo o desenvolvimento de um "pegador" a vácuo que tem seu princípio de funcionamento a aderência em qualquer superfície plana, através do vácuo criado pelo mesmo. Esse pegador irá criar a "pega" perfeita para qualquer tipo de objeto que tenha uma superfície lisa.

\section{REFERENCIAL TEÓRICO}

\subsection{Ergonomia}

A ergonomia é uma ciência que ao contrário das demais áreas do conhecimento, tem uma data de nascimento oficial, sendo esta no dia 12 de julho de 1949. Nessa data reuniu-se um grupo de cientistas e pesquisadores em uma cidade da Inglaterra com a finalidade de 


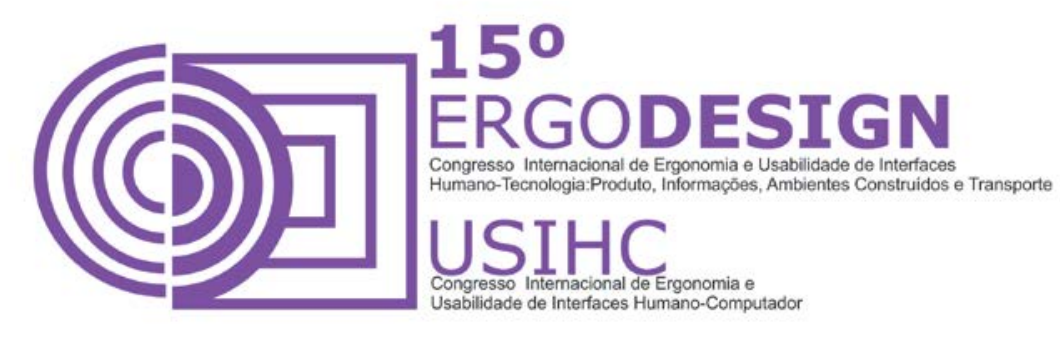

discutir e formalizar essa nova área de aplicação da ciência, que se trata da adaptação do trabalho ao homem. Inicialmente o campo de aplicação da ergonomia era exclusivamente nas indústrias e se concentrava no binômio homem-máquina (IIDA, 2005, p. 5).

A ergonomia pode ser entendida como a adaptação do trabalho ao homem, garantindo sua segurança, produtividade, qualidade de vida e bem estar. Essa adaptação abrange não apenas aquele trabalho realizado por meio de ferramentas ou equipamentos, usados para transformar os materiais. Ela abrange também, toda a situação que envolva o homem com uma atividade produtiva. Levando em conta atividades que acontecem antes, durante e depois dessa atividade produtiva (IIDA, 2005).

Segundo Shida e Bento (2012), a ergonomia é fundamental na adequação de um ambiente ocupacional, pois aplica teoria, princípios e métodos para projetar um local adequado que otimize e proporcione bem estar humano e melhore o desempenho e qualidade de um sistema. De acordo com Guérin (2001), a primeira finalidade da ergonomia é a transformação do trabalho, sendo que para o ergonomista essa transformação tem por objetivo contribuir para: estabelecer formas de trabalho que não alterem a saúde dos operadores; e alcançar os objetivos econômicos determinados pela empresa.

\subsection{Levantamento de Carga}

Souza (2011) define a movimentação manual de cargas como sendo o levantamento e o transporte de peso, incluindo levantar, baixar, sustentar, puxar ou empurrar, sendo considerado um trabalho físico pesado que exige um esforço muscular muito intenso do trabalhador podendo levar a distensões músculo-ligamentares, compressão de estruturas nervosas e fadiga.

Em 1981, NIOSH desenvolveu uma equação para avaliar a manipulação de cargas no trabalho, sendo criada uma ferramenta para diagnosticar os riscos de distúrbios osteomusculares associados à carga física que o trabalhador está submetido e indicar um limite de peso apropriado para cada ocupação, de maneira que uma determinada porcentagem da população pudesse realizar sua tarefa sem risco de desenvolver algum tipo de lesão. Em 1991, a equação foi verificada e novos fatores foram inseridos: a manipulação assimétrica de cargas, o tempo da tarefa, a frequência dos levantamentos e a qualidade da pega (RIBEIRO et al, 2009).

A equação NIOSH é baseada no conceito de que o risco de distúrbios osteomusculares aumenta com a distância entre o limite de peso preconizado e o peso efetivamente manejado. Assim, essa equação estipula o cálculo do índice de levantamento (IL), que é obtido pelo quociente entre o peso da carga levantada ou o peso real (PR) e o peso da carga recomendada (LPR) (RIBEIRO et al, 2009).

A elaboração dessa equação levou em conta três critérios: o biomecânico, fisiológico e psicofísico (ROSSO e OKUMURA, 2007).

A equação estabelece um valor de referência de $23 \mathrm{~kg}$ que corresponde à capacidade de levantamento no plano sagital, de uma altura de $75 \mathrm{~cm}$ do solo, para um deslocamento vertical de $25 \mathrm{~cm}$, segurando-se a carga a $25 \mathrm{~cm}$ do corpo. Essa seria a carga aceitável para $99 \%$ dos homens e $75 \%$ das mulheres sem provocar nenhum dano físico, em trabalhos 


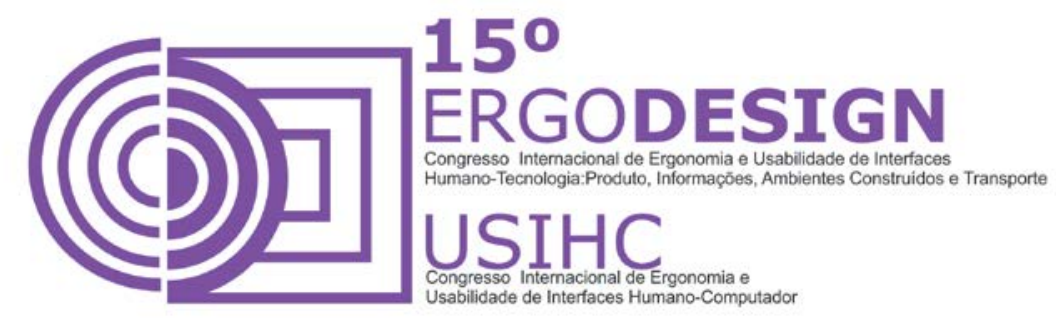

repetitivos. Esse valor de referência é multiplicado por 6 fatores de redução, que dependem das condições de trabalho. São definidas as seguintes variáveis (IIDA, 2005):

$$
\text { LPR }=23 \times(25 / \mathrm{H}) \times(1-0,003 /[\mathrm{V}-75]) \times(0,82+4,5 / D) \times(1-0,0032 \times \mathrm{A}) \times \mathrm{F} \times \mathrm{C}
$$

Onde: LPR=limite de peso recomendável; $\mathrm{H}=$ distância horizontal entre o indivíduo e a carga (posição das mãos) em $\mathrm{cm} ; \mathrm{V}=$ distância vertical na origem da carga (posição das mãos) em $\mathrm{cm} ; D=$ deslocamento vertical, entre a origem e o destino, em $\mathrm{cm} ; A=$ ângulo de assimetria, medido a partir do plano sagital, em graus; $F=$ frequência média de levantamento em levantamentos/min; $\mathrm{C}=$ qualidade da pega.

O resultado da equação de NIOSH é o LPR: limite de peso recomendável. Assim, o peso real carregado pelo trabalhador não deve ultrapassar o LPR, realizando-se assim a análise de levantamento de carga.

De acordo com Moraes et al. (2013), é possível determinar de uma forma quantificada o risco de lesão muscoesquelética através do Índice de Levantamento (IL). De acordo com o $\mathrm{IL}$, pode-se classificar como: baixo (IL $<1)$, moderado $(1 \leq \mathrm{IL}<2$ ) ou alto segundo(IL $\geq 2)$. $\mathrm{O}$ IL é dado através da seguinte equação:

$$
\text { IL= PL/LPR }
$$

Onde: IL = índice de levantamento; $\mathrm{PL}=$ peso levantado; $\mathrm{LPR}=$ limite de peso recomendado.

\subsubsection{Qualidade da Pega}

O fator pega é uma variável estipulada no método de NIOSH, podendo variar de acordo com a Imagem 2:

\begin{tabular}{|c|c|c|}
\hline Pega & $V C>75 \mathrm{~cm}$ & $V C<75 \mathrm{~cm}$ \\
\hline Boa & 1,00 & 1,00 \\
\hline Razoável & 0,95 & 1,00 \\
\hline Pobre & 0,90 & 0,90 \\
\hline
\end{tabular}

Fifura 2: Fator pega para o método de NIOSH. Fonte: Elaborado pelos autores.

Segundo Souza (2011), para um trabalho em boas condições é necessário que o trabalhador segure a carga firmemente com as duas mãos, agarrando-a com as palmas e não apenas com alguns dedos, sendo que para isto as cargas devem ter pegas, como alças ou furos laterais, sendo consideradas pegas nas melhores condições segundo o método de $\mathrm{NIOSH}$.

O estudo apresentado por Pan et al. (2003) apud Azevedo (2011) demonstra que as condições de carregamento como o cetro de massa estão associadas à existência ou 


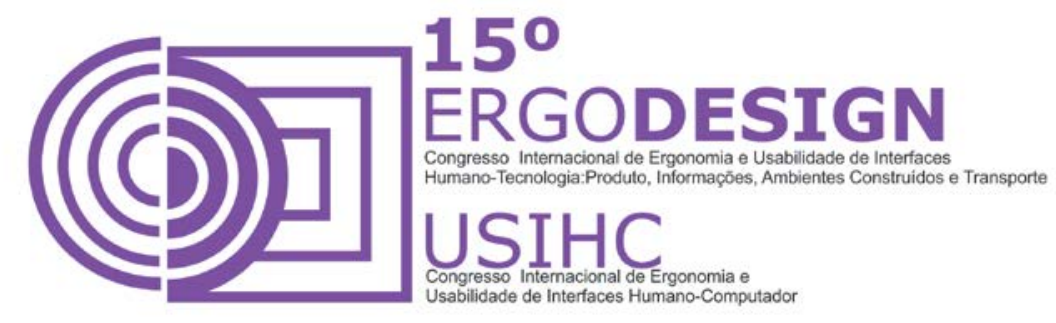

ausência de pegas que facilitem a elevação do objeto, assim como à postura adotada pelo sujeito para elevar a carga.

De acordo com Couto (2002) a qualidade da pega pode ser definida através de alguns fatores, como é possível observar na Figura 3.

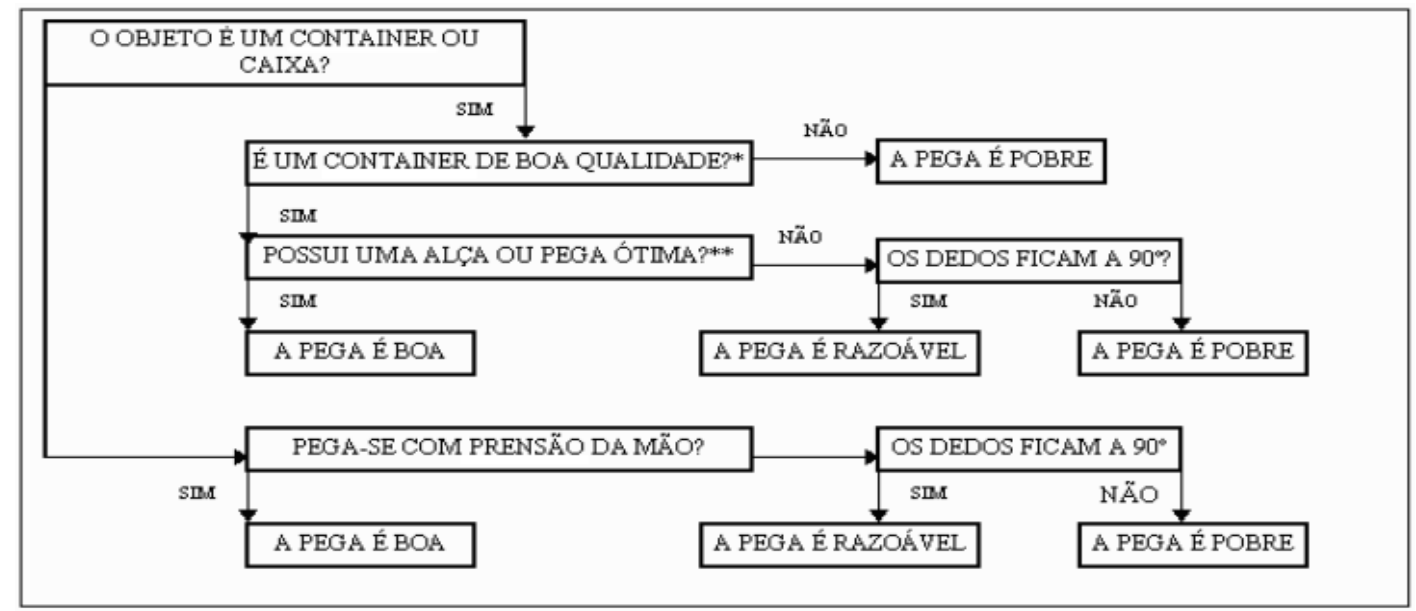

Figura 3: Fluxograma para definição da qualidade da pega. Fonte: Couto, 2002.

\subsection{Projeto de produto}

Para Kotler (2000), produto é algo que pode ser oferecido a um mercado para satisfazer uma necessidade ou desejo. A inovação é um fator vital para o sucesso dos negócios, com isso as empresas devem buscar qualidade, para que ela consiga se garantir no mercado em um alto nível de competitividade (BAXTER; 2000). Segundo Ittner et al. (2004), é importante que os produtos atendam as necessidades e expectativas dos clientes, sendo viável economicamente para a empresa.

O objetivo do projeto de produto, segundo Cunha (2001), é determinar características do produto, sendo um processo que primeiramente avalia as necessidades e desejos do consumidor e tem fim na avaliação positiva do protótipo a ser produzido.

Baxter (2000) caracteriza o desenvolvimento de um produto em três regras básicas do projeto sistemático, que consistem em:

- Estabelecer metas para o desenvolvimento de novos produtos, sendo que elas devem ser claras, concisas, específicas e verificáveis.

- Acompanhar o processo de geração de um novo produto durante várias etapas, comparando aquilo que foi realizado com as metas estabelecidas.

- Ser criativo. Gerar muitas ideias para que possa selecionar a melhor. Não se intimide em apresentar ideias que possam ser consideradas inviáveis numa etapa posterior. 


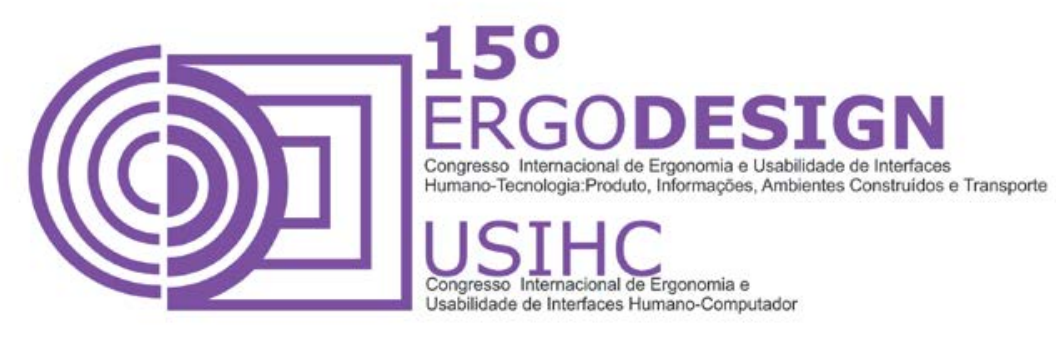

Segundo lida (2005), para o desenvolvimento de um produto é necessário que envolva ideias voltadas à ergonomia, pois a qualidade ergonômica do produto que garante boa interação deste com o usuário.

As características técnicas desejáveis no produto final, segundo lida (2005) destinam-se a satisfazer a certas necessidades humanas e, dessa forma, direta ou indiretamente, entram em contato com o homem. As características básicas de um produto ergonômico são:

- Qualidade técnica: refere-se ao funcionamento do produto, tendo em vista os aspectos mecânicos, elétricos, eletrônicos ou químicos. Esse aspecto leva em consideração a eficiência com que o produto exerce sua função, seu rendimento na conversão de energia e a capacidade de realização de trabalho.

- Qualidade ergonômica: garantia da boa interação do produto com o usuário. Inclui a facilidade de manuseio, adaptação antropométrica, facilidades de "navegação" e demais itens de conforto e segurança.

- Qualidade estética: A qualidade estética é a que proporciona prazer ao consumidor. Envolve a combinação de formas, cores, materiais, texturas, acabamentos e movimentos, para que os produtos sejam considerados atraentes e desejáveis, aos olhos do consumidor.

\section{METODOLOGIA}

A metodologia usada para o projeto foi baseada em modelos de Projeto de Produto (PDP) descritas na fundamentação teórica, assim como os conhecimentos adquiridos durante o transcorrer da disciplina de Projeto de Produto, além de outros conhecimentos adquiridos através de pesquisas de artigos relacionados ao assunto. O objetivo é criar uma ação efetiva, ou resolver um problema, enquanto se aumenta o conhecimento científico (COUGHLAN e COGHLAN, 2002; THIOLLENT, 1997).

Para tanto, a metodologia adotada neste projeto é composto das etapas que serão descritas a seguir:

\subsection{Geração do Conceito}

A geração do conceito consistiu no estudo preliminar visando à definição de mercado, expectativa de clientes, especificações e funções deste produto, qualidade e análise de viabilidades para daí o conceito do produto ser formulado.

\subsection{Geração de Ideias}

A primeira etapa da fase geração do conceito compreende a geração de ideias. Aqui os membros da equipe procuraram idealizar um produto que fosse inovador, útil, técnico e economicamente viável e de baixa complexidade, de forma que fosse possível a confecção do seu protótipo.

Utilizando a técnica de Brainstorming, o grupo teve várias ideias e dentre elas, a equipe optou por solucionar um problema ergonômico relacionado ao carregamento manual de cargas, criando o produto "pega fácil". Tal produto facilita esta atividade, uma vez que, 


\section{(C)] ERT}

proporcionará uma pega ótima (estabelecida pelo método de $\mathrm{NIOSH}$ ) para todos seus usuários.

Tal fato se configura como oportunidade para a entrada do produto no mercado, pois o problema demanda uma solução de curto prazo que possa ser mais aceita pelos usuários.

\subsection{Avaliações Iniciais de Viabilidade}

Nesta etapa, geralmente, é elaborado um estudo de viabilidade técnica, econômica, comercial e avaliação dos impactos ambientais e sociais relativas ao produto proposto. No modelo utilizado, por ser para fins didáticos, essa etapa foi reduzida.

A equipe se dedicou a pesquisar sobre produtos similares ao proposto e a possibilidade de já haver este produto no mercado, portanto foi realizada uma pesquisa no site do Instituto Nacional da Propriedade Industrial (INPI) a fim de averiguar a existência de patentes relacionadas ao produto proposto. A pesquisa foi realizada no mês de novembro de 2014. Para todas as pesquisas realizadas no site não foram encontrados produtos com nomes similares.

Foram abordados pontos importantes utilizados nesse estudo de viabilidade, como: publico alvo, aspectos críticos determinantes do sucesso ou fracasso do novo produto, aspectos que geram incertezas em relação ao mercado consumidor, necessidades pressupostas dos consumidores e benefício básico do produto para o consumidor.

\subsection{Especificação de Oportunidades}

Esta é a fase em que os dados obtidos na fase anterior foram analisados mais profundamente. Através de uma rápida descrição de algumas características, foram determinados os aspectos que poderiam determinar o sucesso/fracasso do produto. Algumas das informações obtidas podem ser vistas na Figura 1.

\begin{tabular}{|c|c|}
\hline Tipo de processo produtivo & $\begin{array}{c}\text { Processo envolvendo a montagem e expedição } \\
\text { dos componentes }\end{array}$ \\
\hline Fatores de sucesso/fracasso do produto & $\begin{array}{c}\text { Marketing, concorrência no setor, maior } \\
\text { preocupação do mercado com ergonomia e } \\
\text { segurança }\end{array}$ \\
\hline Benefício básico & $\begin{array}{c}\text { Redução dos esforços no levantamento e } \\
\text { transporte manual de cargas }\end{array}$ \\
\hline Publico alvo & $\begin{array}{c}\text { Operários industriais e pessoas que trabalham } \\
\text { com transporte de cargas em geral }\end{array}$ \\
\hline Principal caráter de inovação & $\begin{array}{c}\text { Otimização de um fator de risco ergonômico } \\
\text { estabelecido por NIOSH }\end{array}$ \\
\hline
\end{tabular}

Figura 1 - Aspectos relevantes do produto. Fonte: Elaborado pelos autores. 


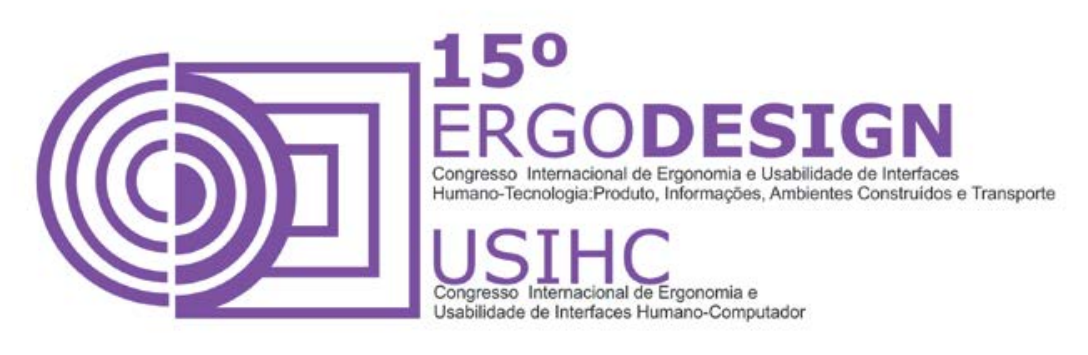

\subsection{Projeto Preliminar}

A etapa do projeto preliminar consistiu na elaboração do projeto estrutural do produto. Esta etapa contempla os desenhos das partes que compõem o produto, as dimensões, os materiais utilizados no mesmo, entre outras características que possam descrever o produto, com um menor grau de detalhes.

O protótipo constitui-se de uma base, a qual foi usada uma desempenadeira, com uma borracha acoplada para vedação de ar, uma seringa e mangueira que vão retirar o ar do ambiente, sendo essa a metodologia para que a pega seja construída.

\subsection{Projeto Detalhado}

Nesta etapa o projeto foi detalhado, suas formas e medidas foram redesenhadas manualmente, as melhorias foram discutidas e implementadas no projeto, para assim, ser feito o desenho final do produto e posteriormente a criação de seu protótipo.

\section{RESULTADO E DISCUSSÃO}

\subsection{Criação e Teste do Protótipo}

A ideia inicial surgiu através do conceito de, melhorar o carregamento de materiais desprovidos de pegas de boa qualidade. Levando em consideração o método de NIOSH que determina as condições para o manuseio de cargas.

O protótipo foi baseado em um produto de laboratório capaz de demonstrar pressão atmosférica. Este produto tem como característica a capacidade de se fixar em superfícies planas pelo fato da pressão exercida pelo lado de fora do material ser maior que a pressão do lado de dentro.

Unindo o conceito da pega com o aparelho de pressão gerou a ideia de construir uma pega manual capaz de ser fixada em superfícies planas.

O desenvolvimento do protótipo se iniciou com a montagem de um pré-projeto. Os objetos foram fixados em uma superfície de madeira, apenas para possibilitar uma visualização de como ficaria a montagem e o tamanho do protótipo. A Figura 4 possibilita a visualização da pré-montagem do protótipo.

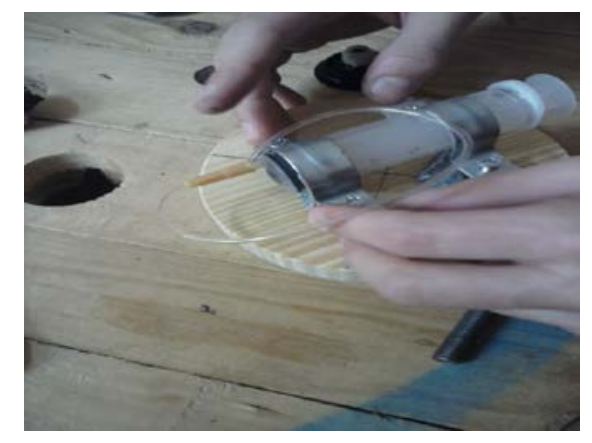

Figura 4: Montagem do pré-projeto. Fonte: Autores. 


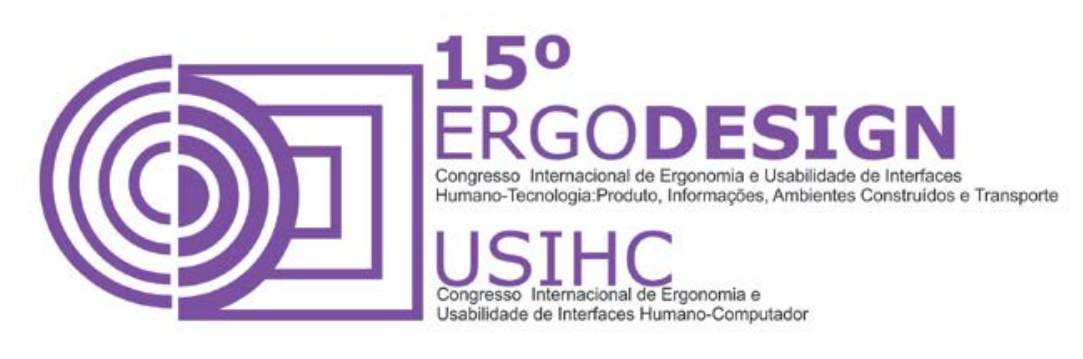

Após a verificação dos quesitos, se iniciou a montagem do protótipo. O objeto escolhido para ser responsável pela retirada do ar de dentro do recipiente é uma seringa, que é ligada por uma mangueira à válvula. Esta válvula faz a ligação da mangueira com a base.

Para impedir a entrada e saída de ar utilizou-se uma borracha, que foi colocada entre a base e a superfície plana do material a ser carregado. Pode-se perceber que na Figura 5 é mostrada a face superior e inferior do protótipo montado.

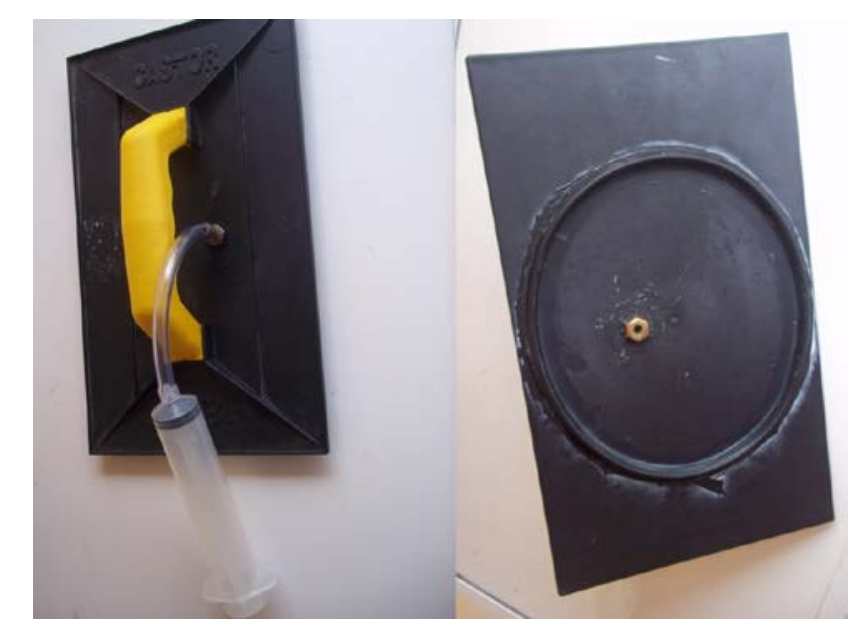

Figura 5: Protótipo da pega manual montado. Fonte: autores.

Após a montagem do protótipo foi necessário fazer testes, afim de, identificar suas capacidades. O primeiro passo foi verificar a capacidade da borracha de vedar a entrada de ar para diferentes tipos de materiais.

Os materiais como vidro, mármore, alumínio, plástico, e materiais pintados e envernizados que possuem superfícies mais regulares apresentam uma capacidade melhor para vedar a entrada e saída de ar, já superfícies de madeira possuem uma capacidade inferior para vedar a passagem de ar. Nestas superfícies foi feita uma média de três tempos de fixação para cada material, sendo que foi considerado um tempo máximo de sessenta minutos para cada medição. Pode se observar na Figura 6, os tempos médios para cada tipo de superfície. 


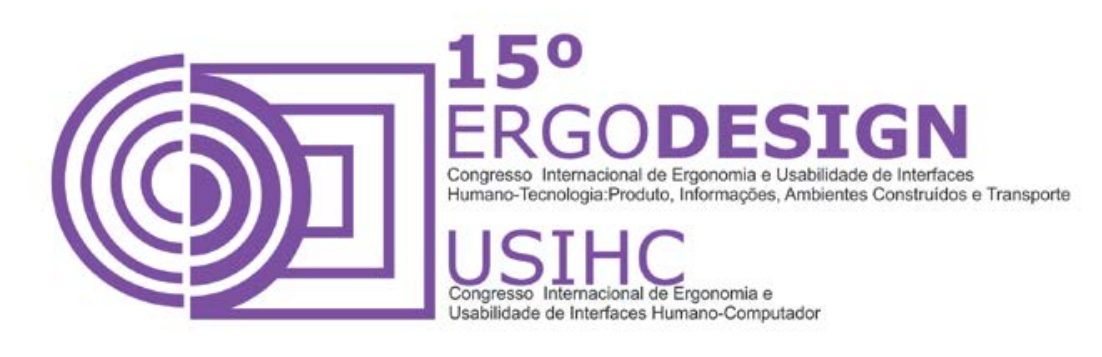

\begin{tabular}{|c|c|c|c|c|}
\hline Material & $\begin{array}{c}\text { Tempo 1 } \\
\text { (minutos) }\end{array}$ & $\begin{array}{c}\text { Tempo 2 } \\
\text { (minutos) }\end{array}$ & $\begin{array}{c}\text { Tempo 3 } \\
\text { (minutos) }\end{array}$ & $\begin{array}{c}\text { Média } \\
\text { (minutos) }\end{array}$ \\
\hline Vidro & 60 & 60 & 60 & 60 \\
\hline Mámore & 50 & 60 & 45 & 51,67 \\
\hline Alumínio & 51 & 43 & 40 & 44,66 \\
\hline Plástico & 27 & 31 & 14 & 24 \\
\hline Madeira & 15 & 20 & 37 & 37,67 \\
\hline $\begin{array}{c}\text { Materiais } \\
\text { pintadose } \\
\text { envernizados }\end{array}$ & 36 & 40 & & \\
\hline
\end{tabular}

Figura 6: Teste de fixação em diversos tipos de Fonte: Elaborado pelos autores.

É possível perceber que o protótipo é mais eficiente em superfícies de vidro, mármore e alumínio, pois estas possuem uma maior regularidade e menor perda de pressão. Em materiais pintados ou envernizados o tempo não se caracteriza muito elevado e nem muito baixo, sendo classificado com um rendimento médio. Já em superfícies como plástico e madeira o tempo é inferior, pois estas apresentam mais irregularidades na superfície. Contudo é importante ressaltar que o protótipo também pode conter brechas em sua estrutura, possibilitando a entrada e saída de ar.

Logo após os testes de vedação foi feito o teste de peso. Nele foram verificados várias cargas acopladas ao protótipo até que este não resistisse e rompesse.

É possível observar na Figura 8 o protótipo elevando uma cômoda feita de madeira envernizada.

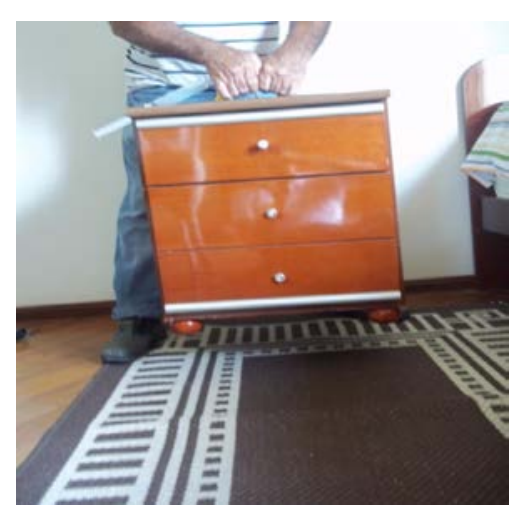

Figura 8: Teste de peso suportado. Fonte: Autores. 


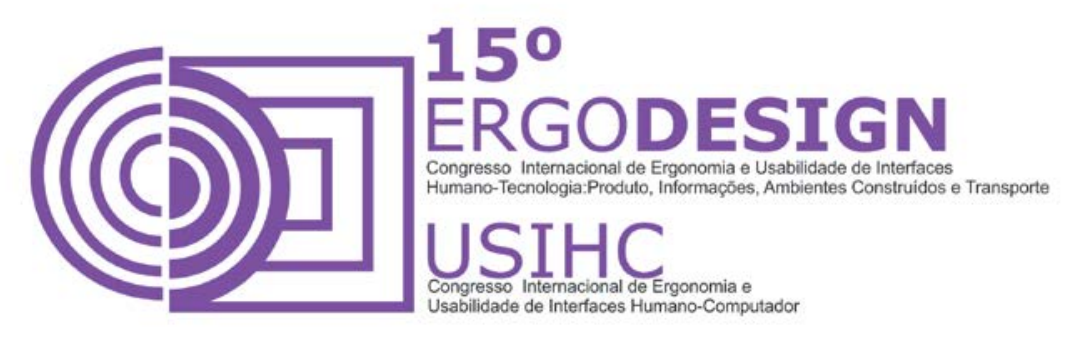

Neste teste foi verificado que o material suportou um limite de até $20 \mathrm{Kg}$ em uma superfície de madeira envernizada, lembrando que esta carga foi suspensa por poucos segundos.

Percebe-se que o protótipo se adéqua a vários tipos de materiais, sendo que as superfícies devem ser planas e regulares. O limite de peso foi consideravelmente alto, uma vez que, segundo lida (2005), o método de NIOSH estabelece o limite máximo de $23 \mathrm{Kg}$ utilizando as duas mãos para o carregamento nas melhores condições. Considerando o peso suportado é possível concluir que utilizando duas pegas será possível o levantamento de $40 \mathrm{Kg}$.

\subsection{Otimização do Método de NIOSH}

Considerando que uma pessoa esteja nas melhores condições para o levantamento de uma carga, ela poderá, segundo o método de $\mathrm{NIOSH}$, alavancar um peso de $23 \mathrm{Kg}$, pois os fatores multiplicadores de redução possuirão valor $=1$.

Levando em consideração que a pega seja pobre o fator de redução será 0,90. O limite de peso recomendado terá uma redução de $10 \%$ comparando com o peso recomendado.

Limite de peso recomendado para uma pega pobre:

$\mathrm{LPR}=23 \times 1 \times 1 \times 1 \times 1 \times 1 \times 0,9$

$\mathrm{LPR}=20,7 \mathrm{Kg}$

Perda de carga devido ao fato do objeto possuir uma pega pobre:

$(2,3 \star 100) / 23=10 \%$

Tendo em mente que, para tais objetos que se dispõem de pegas pobres possa se utilizar o protótipo proposto neste trabalho, o limite de peso recomendado ganha um acréscimo de $11,11 \%$ em relação ao peso máximo, que até então seria o limite sugerido para o carregamento com uma pega pobre.

$(2,3 * 100) / 20,7=11,11 \%$

Visto que o limite de peso recomendado sofre mudanças com a alteração da qualidade da pega, o índice de levantamentos também será alterado, sendo que consequentemente diminuirá o risco de lesões causadas pelo levantamento de cargas.

\section{CONCLUSÃO}

Diante dos estudos realizados é possível perceber a importância de adotar medidas ergonômicas dentro de uma atividade desenvolvida, seja ela no ambiente de trabalho como no ambiente doméstico.

O desenvolvimento da pega manual para o carregamento de objetos com superfícies planas, além de possibilitar uma melhor condição para o carregamento de carga, concede a otimização da equação de NIOSH, e diminui o risco de lesões.

O protótipo testado suporta pesos de até $20 \mathrm{Kg}$, e se aplica a diversas superfícies planas como: vidro, mármore, alumínio, aço, plástico e madeira. Contudo é possível perceber que o produto se faz útil a vários tipos de funções e surge como um meio alternativo para o melhoramento ergonômico da atividade de levantamento de carga. 


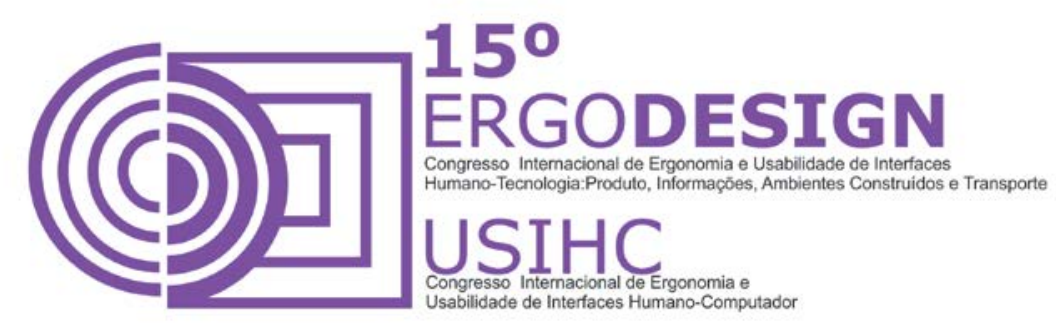

\section{REFERÊNCIAS BIBLIOGRÁFICAS}

ASSOCIAÇÃO BRASILEIRA DE ERGONOMIA (ABERGO). O que é ergonomia. Disponível em: http://www.abergo.org.br/internas.php?pg=o_que_e_ergonomia.

AZEVEDO, R. Acidentes em operações de movimentação manual de cargas na construção. Universidade do Minho, 2011.

BAXTER, M. Projeto de produto: guia prático para o design de novos produtos. 2 ed. Edgard Blücher; São Paulo, 2000.

COUGHLAN, Paul; COGHLAN, David.Action Research for operations management. International Journal of Operations \& Production Management, v.22, n.2, p.220-240, 2002. THIOLLENT, Michel. Pesquisa-ação nas organizações. São Paulo: Atlas, 1997.

COUTO, Hudson A. Ergonomia Aplicada ao Trabalho em 18 Lições. Belo Horizonte: Ergo, 2002.

CUNHA, G. D. Desenvolvimento de produto. Apostila de desenvolvimento de produto do curso de mestrado em engenharia de produção. UFRGS: Porto Alegre, 2001.

GUÉRIN, F. et al. Compreender o trabalho para transformá-lo: a prática da ergonomia. São Paulo-SP, 2001.

IIDA, Itiro. Ergonomia: Projeto e produção. 2a edição. São Paulo: Blucher, 2005.

ITTNeR, A. E.; TREnTIN I. L.; PINI N. G. F.; HOUnSELL, M. S.. Projeto de Produto. Udesc. Joinvile-SC, 2004.

KOTLER, P. Administração de marketing.10 ed. Pretice Hall: São Paulo, 2000.

MORAES, A. C.; MINETTE, L. J.; SOUZA, A. P.; SILVA, E. P.; SACHES, A. L. P.. Biomecânica como ferramenta ergonômica para análise do trabalho florestal. III Encontro Mineiro de Estudos em Ergonomia, 2013.

RIBEIRO, Ivan Augusto Vall; TERESO, Mauro José Andrade; ABRAHÃO, Roberto Funes. Análise ergonomia do trabalho em unidades de beneficiamento de tomates de mesa: movimentação manual de cargas. Ciência Rural. Santa Maria, 2009.

ROSSO. André Luiz Barp; OKUMURA, Sérgio. Estudo comparativo entre o peso suportado pelos trabalhadores no transporte manual de sacas de cimento e o limite recomendado pelo método NIOSH. Trabalho De Conclusão De Curso, Graduando Em Engenharia De Segurança Do Trabalho. Universidade Do Extremo Sul Catarinense, Criciúma, 2007.

SHIDA, G. J.; BENTO, P. E. G.. Métodos e ferramentas ergonômicas que auxiliam na análise de situações de trabalho. VII Congresso Nacional de Excelência em Gestão. UFSCar, 2012.

SOUZA, C. B. M.. Incidência de lombalgia na movimentação manual de cargas na indústria química de base de pequeno porte. UNESC. Criciúma-SC, 2011. 